Ann. Biol. anim. Bioch. Biophys., I968, 8 (3), 457-459.

\title{
INFLUENCE D'UNE DIMINUTION DU TAUX PROTÉIQUE DE LA RATION SUR LES TENEURS EN ACIDES AMINES LIBRES DES TISSUS SANGUIN ET MUSCULAIRE DU RAT EN CROISSANGE
}

\author{
M. PAWLAK, R. PION \\ Station d'étude des Métabolismes, \\ Centre de Recherches zootechniques et vétérinaires, sur les Ruminants \\ 63 - Theix, près Clermont-Ferrand \\ Institut national de la Recherche agronomique
}

Nous avons constaté (PAWLAK et PION $a, b$ ) que, chez des änimaux dont les besoins en nutriments autres que l'acide aminé étudié sont couverts, il existe une relation directe entre les teneurs en lysine et en thréonine libre des tissus sanguin et musculaire et leurs teneurs respectives dans l'aliment. Nous avons cherché dans la présente étude à déterminer l'influence d'une diminution des apports alimentaires de l'ensemble des acides aminés sur les concentrations en acides aminés libres de ces tissus. Nous avons pour cela utilisé comme précédemment des aliments isoénergétiques, ne contenant comme matières azotées que celles du blé, supplémentées en lysine, thréonine, tryptophane et méthionine, dans les mêmes proportions dans les différents régimes (tabl. $\mathrm{I}$ ). L'aliment dont le taux protéique était le plus élevé correspondait sensiblement au besoin des animaux, mais con: tenait un léger excès de thréonine, et était légèrement carencé en isoleucine. Les deux autres régimes contenaient respectivement $90 \mathrm{p}$. I00 et $70 \mathrm{p}$. Ioo de ces taux. Les animaux, pesant $100 \mathrm{~g}$ au début de l'expérience, étaient répartis en lots de 8; et la durée de la période expérimentale était de 18 jours. Les conditions d'élevage des animaux, de prélèvement des échantillons et d'analysé (Mooré, Spackiman et Stein, 1958) ont été décrites précédemment (Pawlak et Pron, I968 a).

Les résultats figurent sur le tableau $2:$ la légère carence en matières azotées des animaux du lot II est partiellement compensée par une légère augmentation de la consommation, et n'entraîne qu'une faible diminution de la croissance. Les concentrations dans les deux tissus de la plupart des acides aminés indispensables"sont peu affectées. La nette diminution de concentration constatée dans le cas de la thréonine correspond à une diminution de l'arcumulation de cet acide aminé ; les teneurs des deux tissus restent en effet supérieures à celles qui correspondent à la satisfaction du besoin (PAWLAK et Pion, 1968 b). Au contraire, les baisses de teneur en isoleucine, et dans le muscle; en méthionine, doivent être la manifestation d'un certain déficit.

Les phénomènes observés dans le cas du taux protéique le plus faible sont bien différents : la consommation est légèrement plus faible ( $9 \mathrm{p}$. 100), et la croissance est fortement diminuée (25 p. 100).

Les concentrations de la plupart des acides aminés indispensables diminuent fortement, aussi bien dans le muscle que dans le sang, et les différences les plus marquées sont obtenues pour la 
TABLEAU I

Composition des régimes

\begin{tabular}{|c|c|c|c|}
\hline \multirow[b]{2}{*}{ · } & \multicolumn{3}{|c|}{ Lots } \\
\hline & I & II & III \\
\hline Taux protéique $(\mathrm{N} \times 6,25) \ldots \ldots \ldots$ & 12,6 & 11,3 & 9,15 \\
\hline Agar-agar...$\ldots \ldots \ldots \ldots \ldots$ & 20 & 20 & 20 \\
\hline 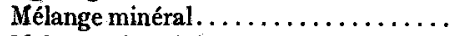 & 45 & 45 & 45 \\
\hline Mélange vitaminique............. & 20 & 20 & 20 \\
\hline DL-Méthionine $\ldots \ldots \ldots \ldots \ldots \ldots \ldots$ & 1,2 & 1,0 & 0,8 \\
\hline L-Thréonine $\ldots \ldots \ldots \ldots \ldots \ldots \ldots$ & 2,3 & 2,0 & 1,6 \\
\hline L-Tryptophane $\ldots \ldots \ldots \ldots \ldots \ldots$ & 0,6 & 0,5 & 0,4 \\
\hline L-Lysine $\mathbf{H C l} \ldots \ldots \ldots \ldots \ldots \ldots \ldots$ & 7,0 & 6,0 & 4,8 \\
\hline Blé $\ldots \ldots \ldots \ldots \ldots \ldots \ldots \ldots \ldots \ldots \ldots \ldots \ldots$ & 814 & 709 & 567 \\
\hline Amidon $\ldots \ldots \ldots \ldots \ldots \ldots \ldots \ldots \ldots$ & 27 & 129,3 & 267,5 \\
\hline Huile $\quad \ldots \ldots \ldots \ldots \ldots \ldots \ldots \ldots \ldots$ & 62,9 & 67,2 & 72,9 \\
\hline
\end{tabular}

TABLEAU 2

Teneurs en acides aminés libres

(en mg pour roo $\mathrm{g}$ de tissu frais)

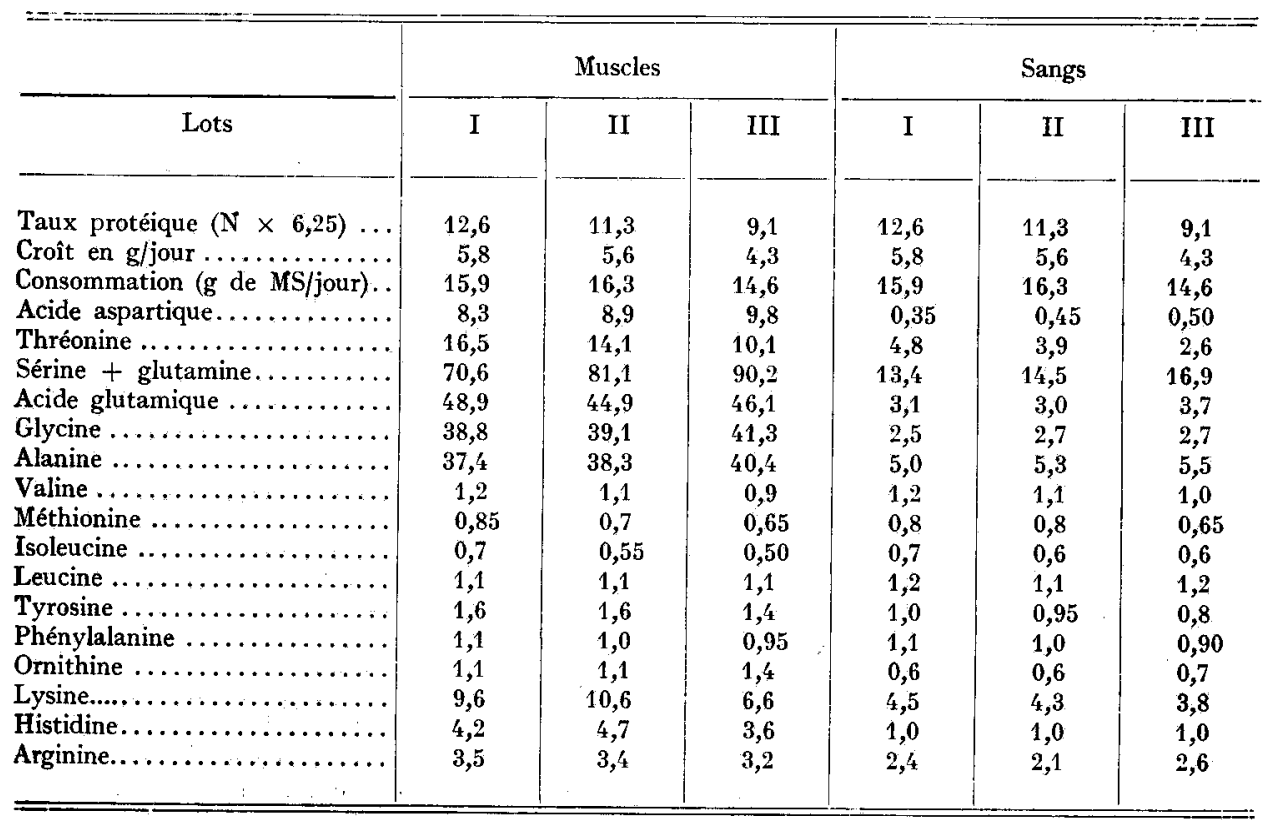


thréonine, la lysine, l'isoleucine, la valine et la méthionine. Toutefois, les valeurs observées pour la thréonine et la lysine sont nettement plus élevées que celles que nous avions observées chez des animaux qui consommaient des taux équivalents de ces acides aminées, mais dont les autres besoins étaient couverts. Les teneurs en leucine dans les deux tissus, et en histidine dans le sang, sont égales à celles que l'on observe dans le cas des animaux consommant le régime le plus riche en azote, et ces acides aminés se trouvent donc présents dans les tissus en proportions élevées par rapport aux autres.

Les teneurs en acides aminés non indispensables tendent à augmenter lorsque le taux protéique de la ration diminue, ce qui montre que l'animal consommant la ration la plus pauvre en matières azotées a, à sa disposion, une quantité d'azote indifférencié supérieure à celle qu'il peut utiliser.

Ces résultats montrent qu'une légère diminution du taux protéique des rations utilisées dans l'étude des concentrations en acides aminés libres du sang et du muscle peut faciliter la mise en évidence des déficits en acides aminés indispensables. Au contraire, la diminution de la synthèse protéique consécutive à une carence trop sévère en acides aminés semble plutôt masquer les déficits, tandis que les teneurs relativement élevées de certains acides aminés (leucine, histidine) laissent supposer qu'ils se trouvent en excès par rapport aux autres.

\title{
Reçu pour publication en juin 1968.
}

\section{SUMMARY}

\author{
EFFECT OF A DECREASE IN THE PROTEIN LEVEL OF THE DIET \\ ON THE FREE AMINOACID CONTENT OF BLOOD AND MUSCLES IN THE GROWING RAT
}

Batches of rats weighing $100 \mathrm{~g}$ were given isoenergetic diets with $\mathrm{I2.6}$, II.3, 9.10 per I00 protein $(\mathrm{N} \times 6.25)$ from whole corn supplemented with lysine, threonine, tryptophane, methionine at identical rates, in an 18 day experiment (table I).

The growth rates, energy utilization and free amino acid content of tissues are given in tabular from (table 2). The two higher protein levels gave similar growth rates, and the intake was scarcely altered. The free aminoacid contents of the tissues decrease in relation with the protein.

The sharpest decrease was observed for the more indispensable amino acids, as threonine and lysine, whereas the less indispensable tend to increase. Therefore, a light decrease in the protein rate of diets allow to increase the lack of indispensable aminoacids when experiments on free aminoacid content of tissues are performed.

\section{RÉFÉRENCES BIBLIOGRAPHIQUES}

Moore S., Spackman D. H., STEIN W. H., 1958. Chromatography of amino acids on sulfonated polystyrene resins. Analyt. Chem., 30, I185-1 190.

PaWlak M., PION R., I968 a. Influence de la supplémentation des protéines de blé par des doses croissantes de lysine sur la teneur en acides aminés libres du sang et du muscle du rat en croissance. Ann. Biol. anim. Biochim. Biophys. (sous presse).

Pawlak M., Pion R., I968 b. Influence sur la supplémentation des protéines du blé par des doses croissantes de thréonine sur les teneurs en acides aminés libres du sang total et du muscle du rat en croissance. C. R. Acad. Sci. Paris, série D, 866, 1993-1995. 